\title{
Experimental Investigation of the Influence for Stoping Sequence and Granular Grading on Lateral Pressure during the Nonpillar Sublevel Caving Mining
}

\author{
Yang Liu, ${ }^{1}$ Rongxing He $\left(D,{ }^{1}\right.$ Fengyu Ren, ${ }^{1}$ Jianli Cao, ${ }^{1}$ Dongjie Zhang, ${ }^{2}$ Yanjun Zhou, ${ }^{1}$ \\ Huan Liu, ${ }^{1}$ Guanghui Li, ${ }^{1}$ and Jing Zhang ${ }^{1}$ \\ ${ }^{1}$ School of Resources and Civil Engineering, Northeastern University, Shenyang 110819, China \\ ${ }^{2}$ Institute of Mining and Coal, Inner Mongolia University of Science and Technology, Baotou 014010, China \\ Correspondence should be addressed to Rongxing He; herongxing@mail.neu.edu.cn
}

Received 16 December 2019; Accepted 2 May 2020; Published 28 May 2020

Academic Editor: Mostafa Sharifzadeh

Copyright (c) 2020 Yang Liu et al. This is an open access article distributed under the Creative Commons Attribution License, which permits unrestricted use, distribution, and reproduction in any medium, provided the original work is properly cited.

\begin{abstract}
In this study, a self-designed scaled physical model was conducted to investigate the variation laws of lateral pressure under different stoping sequences and granular gradings, and drawing ore in the experiments was used to simulate the mining process. Under the limiting equilibrium state, the values of lateral pressure increased exponentially with the increasing depth of granular media, and the growth rate of lateral pressure gradually decreased as the depth of granular media increased. Then, the laboratory results indicated that the distribution laws of lateral pressure were divided into three parts, namely, the drawing influencing region, the upper descending zone, and the central growth area. As the height of the isolated extraction zone (IEZ) increased, the scope of the drawing influencing region and the upper descending zone increased, while the range of central growth area decreased. In the case of an invariable height of IEZ, more reduction ratio and the scope for drawing influencing region could be appeared in the lower wall. Increasing the space between the drawpoints and granular grading were an effective way to control the reduction rate of lateral pressure in the drawing influencing region, while the scope of the above parts kept stable. Moreover, the average values of lateral pressure showed an increasing trend as the granular grading decreased at the same number of drawing ore.
\end{abstract}

\section{Introduction}

The nonpillar sublevel caving mining was usually adopted to extract the underground metal mine, which has a high mining intensity, consumes little mining costs, and uses simple stoping technology [1-3]. However, the surface subsidence was inevitably generated in the vicinity of the mining operations based on the main characteristic of this mining method. The inaccurate range of the surface subsidence could significantly deteriorate recovery ratio, the loss of natural resources, and operational safety. Meanwhile, the distribution laws of lateral pressure were the essential factor to predict the range of surface subsidence induced by the nonpillar sublevel caving mining [4-7]. Hence, it was quite essential to investigate the distribution laws to control and avoid the loss of natural resources and jeopardizes surface subsidence.

Recently, many great efforts had made to study the distribution laws of lateral pressure using physical models, theoretical analyses, and numerical analyses. Meanwhile, the conventional laws of lateral pressure are based on the theory of Janssen, Coulomb, Reimbert, Wilfred Airy, and Rankine and then the widespread computational formulas of lateral pressure as shown in Table 1 [8-19]. The theory of Janssen had been widely used, but the different coefficient of lateral pressure was applied in the different specifications. Reimbert [14] studied the equation based on laboratory tests, where the coefficient of lateral pressure was variable. Then, Chen [17] reported a formula of lateral pressure with an inclined angle according to the assumption of the Janssen equation, 


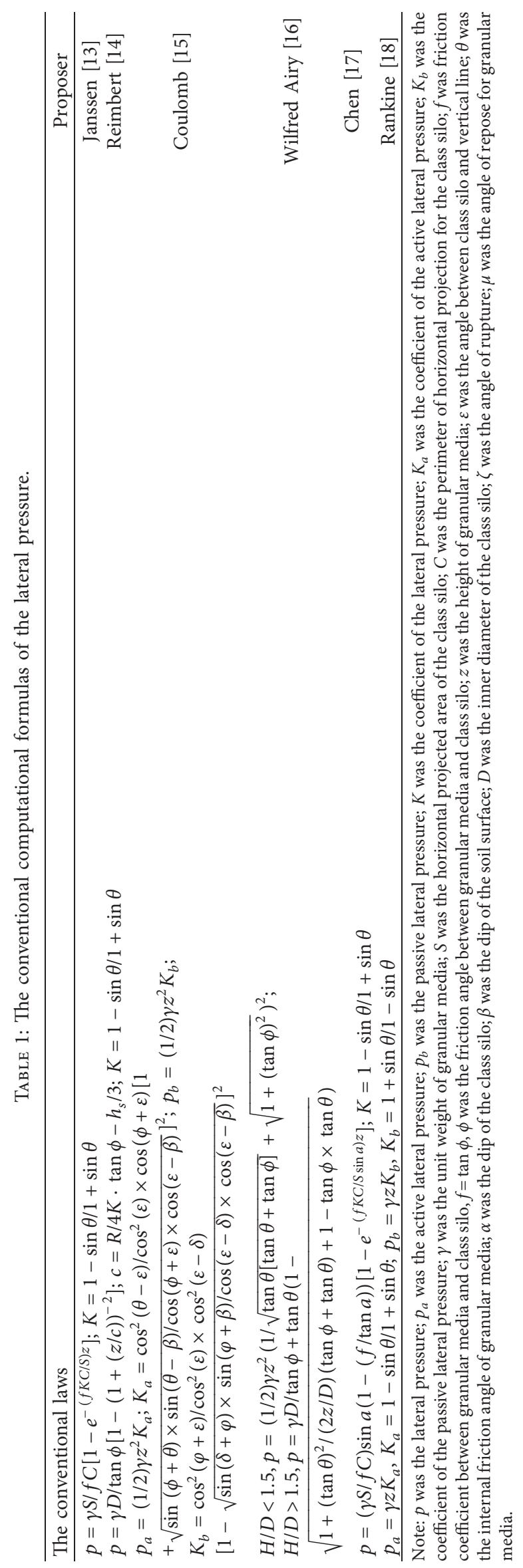


which had been used in thin orebody. Otherwise, the scaled physical experiments had been widely utilized in the laboratory, with low cost, simpler operation, and low time consumption. Brown et al. researched the patterns of pressures in storage and discharge state with two different free-flowing solids [20]. Meanwhile, Ren et al. designed the setup to study the variation laws of lateral pressure during the process of drawing ore [21]. With the development of numerical simulation technique, a mass of number codes, including ANSYS [22, 23], DEM [24, 25], and PFC [26], were developed and applied in the models of lateral pressure for granular media. The PFC3D software was employed to simulate the distribution laws for internal pressure of the material during the coal discharging process [27], and the ADINA software was performed to predict the value of lateral pressure in the silo [28]. These studies had provided a critical understanding, including the distribution laws of lateral pressure under the limiting equilibrium state, the influence on the lateral pressure among materials, the influencing factors of the geometry for bin shape, and the coefficient characteristic for the lateral pressure and its changing trend.

In nonpillar sublevel caving mining, the movement and nonuniform granular conditions of granular media for the caved rock zone were very common $[29,30]$. Thus, the distribution laws of lateral pressure were influenced by mining. However, most of these studies had focused on the distribution laws for lateral pressure at the limiting equilibrium and uniform granular conditions. Few investigations were reported for the distribution laws under the drawing ore and nonuniform grading conditions. Although some important factors such as the size of drawpoint, the properties of the material, and the dip and width of orebody could affect the lateral pressure, the stoping sequence and granular grading were also vital to analyze the stress states of side wall for surface subsidence. Considering the influence of the stoping sequence and granular grading on the distribution laws of lateral pressure, scaled physical experiments were carried out, and the variation laws of lateral pressure during drawing ore were found in this study. This work could not only help researchers to understand the mechanism of gravity flow for granular media, but also provided a theoretical tool for predicting the scope of the surface subsidence induced by the nonpillar sublevel caving mining.

\section{Materials and Model}

Castro et al. [31] reported that the shape of the isolated extraction zone (IEZ) was not significantly affected by the geometrical scale using a large 3D physical model. To reduce the effect on the operation or flow capability, the setup should be rational and feasible. Thus, some hypotheses of scaling were applied as follows: (1) the geometrical scale of 1 : 100 was used to simulate for the whole block geometry, including block dimensions (height and area of draw), the dimensions of drawpoint, and the particle size; (2) the bulk density and the residual friction angle in the model were the same as those in the field; (3) the wall friction angle was similar to the internal friction angle; and (4) the scale of times was related to the scale of the length by $\lambda_{t}=100^{1 / 2}=10$.

The equipment was composed of a drawing-ore device, a data collection system, and a supporting bar for adjusting the orebody dip, as shown in Figure 1. As shown in Figure 2, the drawing-ore device was made up of upper and lower walls, front and back walls, drawpoints, and test channels, with the size of $50 \mathrm{~cm} \times 25 \mathrm{~cm} \times 160 \mathrm{~cm}$ (width $\times$ length $\times$ height). The granular media in the drawing-ore device was required to measurably stable during the experimental process. Hence, the walls of lower and upper were made from steel. Then, four drawpoints (the length and width of them were both $3 \mathrm{~cm}$ ) were set in the bottom of the lower wall, and the interval was $7.6 \mathrm{~cm}$. Also, the drawpoints were used to simulate the different stoping sequences. To precisely obtain the values of lateral pressure, the upper and lower walls were made up of 16 panels, respectively, and the corresponding size was $50 \times 10 \mathrm{~cm}$ (width $\times$ length). Then, $1 \#-8 \#$ test channels were placed in the lower wall and 9\#-16\# test channels were installed in the upper wall, and the interval was $20 \mathrm{~cm}$ in the respective wall. 1\# and 9\# test channels were $15 \mathrm{~cm}$ away from the bottom of the device, and 8\# and 16\# test channels were $5 \mathrm{~cm}$ away from the top of the device. The test channels collected information regarding the lateral pressure with different measured heights, and the measured height of each test channel is shown in Table 2. Then, the values of lateral pressure with different heights were transferred from the test channels to the data collection system during the drawing process. In the study, the stoping sequence and granular grading were investigated as influencing factors to possess the distribution laws of lateral pressure during drawing ore. Dolomite was used as the experimental material in the test and was regarded as cohesionless.

\section{Experimental Process}

The basic operation and theoretical foundation of the isolated drawing experiments were provided by Zhang et al. [32]. A total of 9 physical simulation tests were designed to study the influence of the stoping sequence and granular grading on the distribution laws of lateral pressure. As shown in Tables 3-5, three different stoping sequences and three granular gradings were taken into account in this study. According to the geometrical scale and nonpillar sublevel caving mining $[1,33]$, the height of orebody $(30 \mathrm{~cm})$ and the drawing mode of nondilution were employed. To keep the ore flow capabilities consistent with the test materials, the ores were obtained directly from the test materials, and their size was in accordance with the test material. Then, the ores were red painted to distinguish them from the test materials. To make the flow velocity of granular media keep constant and full similitude of mine conditions, the single mass of the ores drawn from the drawpoints was about $200 \mathrm{~g}$ per time and the independent advance of ore breaking was approximately $1.5 \mathrm{~cm}$. Moreover, each experiment was repeated 3 times to decrease the influence of random movements of experimental materials based on the flow behaviors during the drawing process. To avoid the influence 


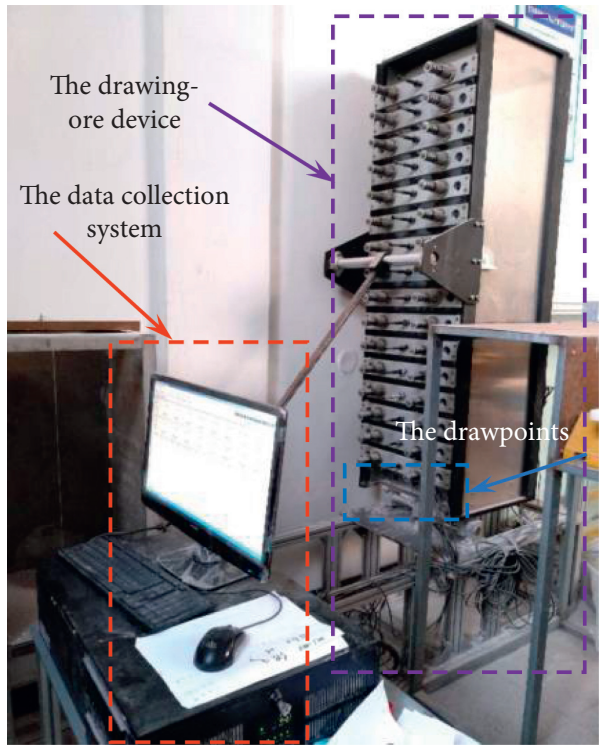

Figure 1: The schematic diagram of the physical model.

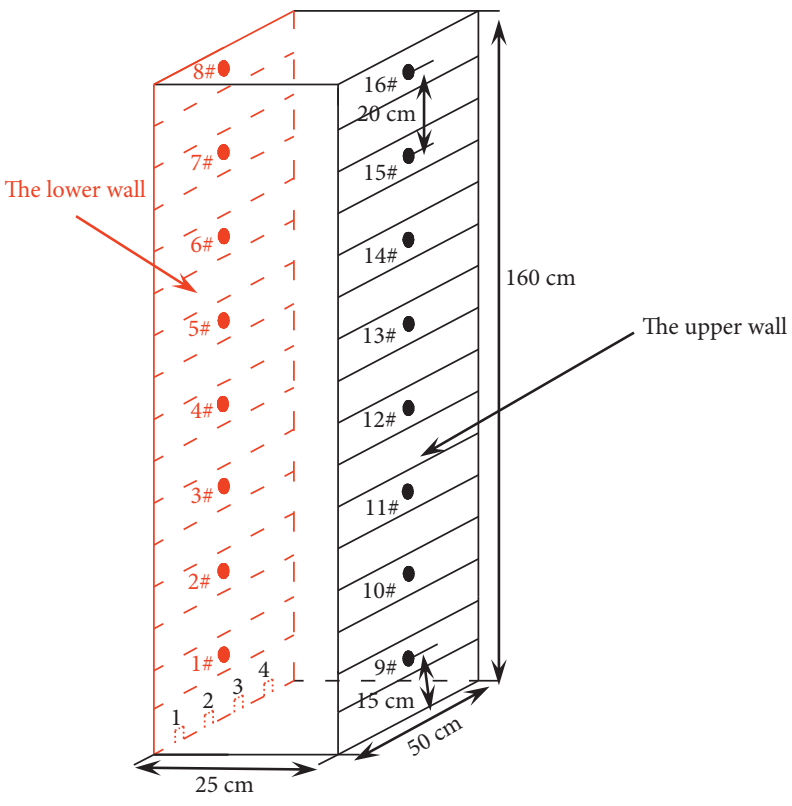

Figure 2: The schematic diagram of the drawing-ore device. Note: $1 \#, 2 \#, \ldots, 16 \#$ represent the test channels, and I, II, III, and V represent the drawpoints.

TABle 2: The measured height of each test channel.

\begin{tabular}{lcccccccccccccccc}
\hline \multirow{2}{*}{ Test channels } & \multicolumn{1}{c}{ The lower wall } & \multicolumn{1}{c}{ The upper wall } \\
& $1 \#$ & $2 \#$ & $3 \#$ & $4 \#$ & $5 \#$ & $6 \#$ & $7 \#$ & $8 \#$ & $9 \#$ & $10 \#$ & $11 \#$ & $12 \#$ & $13 \#$ & $14 \#$ & $15 \#$ & $16 \#$ \\
\hline Measured height $(\mathrm{m})$ & 1.45 & 1.25 & 1.05 & 0.85 & 0.65 & 0.45 & 0.25 & 0.05 & 1.45 & 1.25 & 1.05 & 0.85 & 0.65 & 0.45 & 0.25 & 0.05 \\
\hline
\end{tabular}

on the testing data, the drawing-ore device was remained horizontal on the ground and the adjusting bar was fixed on the experimental model.
After completing the above steps, the drawpoints were blocked with the elastic materials so as to simulate the real state without blasting. Then, the incompact ores were 
TABLe 3: Summary of laboratory schemes.

\begin{tabular}{lccc}
\hline Granular grading & Stoping sequence & \\
& Interval faces & From center to end & From end to center \\
\hline Group 1 & Scheme 1 & Scheme 4 & Scheme 7 \\
Group 2 & Scheme 2 & Scheme 5 & Scheme 8 \\
Group 3 & Scheme 3 & Scheme 6 & Scheme 9 \\
\hline
\end{tabular}

TABle 4: Summary of stoping sequence.

$\begin{aligned} & \text { Stoping sequence } \\ & \text { Interval face }\end{aligned}$
$\begin{array}{r}\text { (1) Unfold the drawpoints of II and V; (2) recorded the values of lateral pressure during the drawing process; (3) } \\ \text { blocked the corresponding drawpoint once the waste rocks were drawn from the drawpoint; (4) let the drawing-ore } \\ \text { device sit for 20 minutes; (5) unfold the drawpoints of I and III; (6) repeated the step of (2) and (3). }\end{array}$
$\begin{aligned} & \text { From center to } \\ & \text { end }\end{aligned}$
$\begin{aligned} & \text { (1) Unfold the drawpoints of II and III; (2) recorded the values of lateral pressure during the drawing process; (3) } \\ & \text { blocked the corresponding drawpoint once the waste rocks were drawn from the drawpoint; (4) let the drawing-ore } \\ & \text { device sit for } 20 \text { minutes; (5) unfold the drawpoints of I and V; (6) repeated the step of (2) and (3). }\end{aligned}$
$\begin{aligned} & \text { From end to } \\ & \text { center }\end{aligned}$
$\begin{aligned} & \text { (1) Unfold the drawpoints of I and V; (2) recorded the values of lateral pressure during the drawing process; (3) blocked } \\ & \text { the corresponding drawpoint once the waste rocks were drawn from the drawpoint; (4) let the drawing-ore device sit } \\ & \text { for } 20 \text { minutes; (5) unfold the drawpoints of II and III; (6) repeated the step of (2) and (3). }\end{aligned}$

TABLE 5: Summary of granular grading.

\begin{tabular}{|c|c|c|c|c|c|c|c|c|c|}
\hline Granular grading & & roup & & & roup & & & Group & \\
\hline The mass percent (\%) & 24.6 & 38.6 & 36.8 & 24.6 & 38.6 & 36.8 & 24.6 & 38.6 & 36.8 \\
\hline The granular size $(\mathrm{mm})$ & $<2$ & $2 \sim 4$ & $4 \sim 6$ & $<3$ & $3 \sim 6$ & $6 \sim 9$ & $<4$ & $4 \sim 8$ & $8 \sim 12$ \\
\hline
\end{tabular}

dropped into the setup with $30 \mathrm{~cm}$, and a smooth surface of the ores would be obtained. Next, the surface of the ores was surrounded by a little waste rock, such that each ore granular was stabilized. Otherwise, the ore granular in the surface would move randomly in the ore loading process, thereby affecting the experimental results. Also, the other incompact waste rocks were dropped into the setup, so no more materials could be dropped into the experimental model. Finally, the total internal space of setup was filled with the experimental materials. Additionally, the internal friction angle and friction angle between granular media and the drawing-ore device were analyzed. Meanwhile, the total mass and density of granular media were calculated once the ore loading process was terminated. Since the internal model was filled with the experimental materials, the elastic material blocking the drawpoints was taken off, and the materials were then drawn from the drawpoints. According to the above scheme, the corresponding drawpoints were unfolded. During the drawing process, the flow speed of granular media should remain as constant as possible rather than fast. Hence, the single mass of the ore drawn from the drawpoints was about $200 \mathrm{~g}$ each time, and the values of lateral pressures and the number of drawing ore were recorded. Then, the corresponding drawpoint was terminated once the waste rocks were drawn. The interval time of 20 minutes was employed to simulate the mining conditions. Then, the next corresponding drawpoints were unfolded and the previous steps were repeated. Consequently, the variation laws of lateral pressure could be received once the waste rock reached the last drawpoint.

\section{Experimental Results}

4.1. The Relationship between Lateral Pressure and Depth of Granular Media. Figure 3 presents the relationship between the lateral pressure and depth of granular media under the limiting equilibrium state. The values of lateral pressure increased exponentially with the increasing depth of granular media, and the growth rate of lateral pressure gradually decreased as the depth of granular media increased. Then, the porosity of granular media increased when the granular grading increased. However, the unit weight decreased accordingly. Hence, the values of lateral pressure showed an increasing trend as the granular grading decreased for the same depth of granular media. Meanwhile, the porosity of granular media decreased as the depth of granular media increased, and the value of lateral pressure among granular grading increased with the increasing depth of granular media.

4.2. Characteristic of Variation Laws for Lateral Pressure. The relationship between the number of drawing ore and the values of lateral pressure with different schemes are shown in Figures 4-12, respectively. Due to the 20-minute interval time, the process of drawing ore could be divided into two stages, and IEZ induced by two drawing stage was independent [34]. It was suggested that the measured values from $1 \#$ and 9\# test channels decreased exponentially with an increasing number of drawing ore in each drawing stage. Then, the lateral pressure of $2 \#, 3 \#$, and 10\# test channels was firstly enhanced and then diminished as the number of 


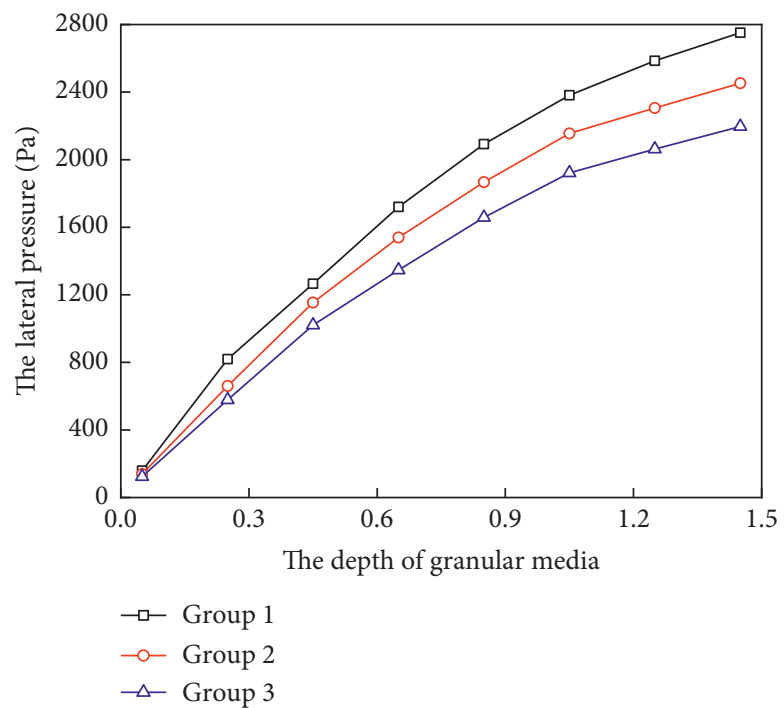

Figure 3: The relationship between the lateral pressure and depth of granular media under the limiting equilibrium state.
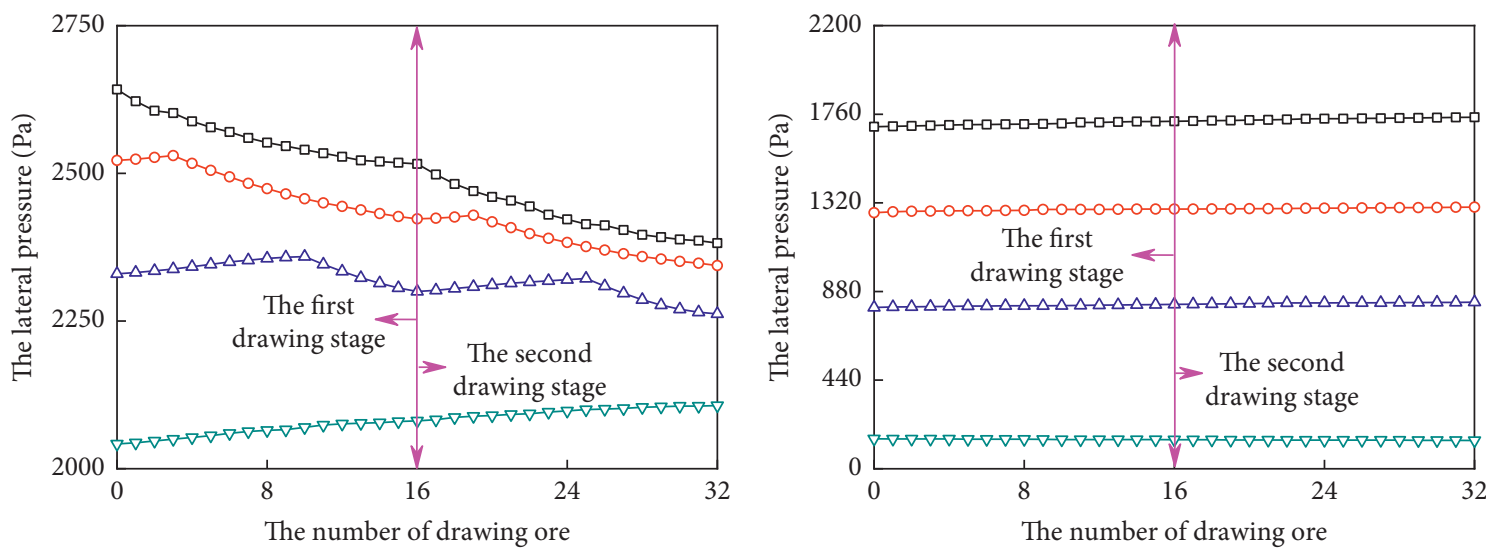

$\begin{array}{ll}\rightarrow-1 \#(h=1.45 \mathrm{~m}) & \rightarrow-3 \#(h=1.05 \mathrm{~m}) \\ \multimap-2 \#(h=1.25 \mathrm{~m}) & \rightarrow-4 \#(h=0.85 \mathrm{~m})\end{array}$

(a)

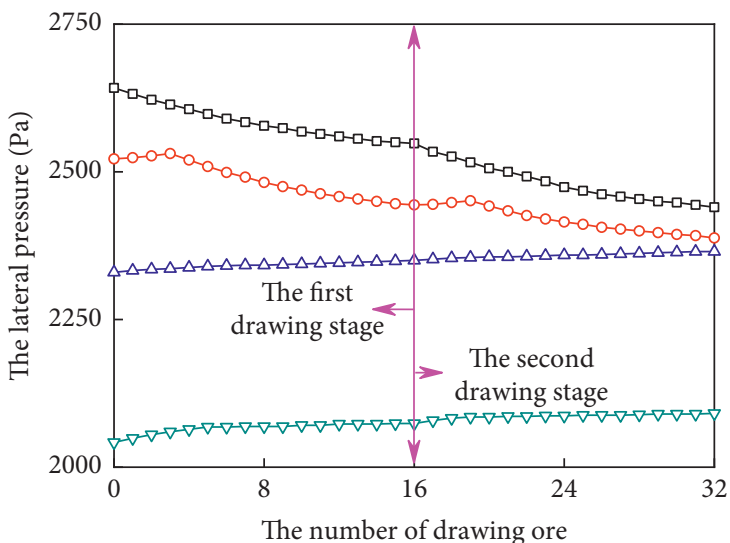

$\rightarrow-9 \#(h=1.45 \mathrm{~m}) \quad \longrightarrow \quad 11 \#(h=1.05 \mathrm{~m})$

$\multimap 10 \#(h=1.25 \mathrm{~m}) \quad \rightarrow-12 \#(h=0.85 \mathrm{~m})$

(c)

$$
\begin{array}{ll}
\rightarrow-5 \#(h=0.65 \mathrm{~m}) & \triangle-7 \#(h=0.25 \mathrm{~m}) \\
\multimap-6 \#(h=0.45 \mathrm{~m}) & \rightarrow-8 \#(h=0.05 \mathrm{~m})
\end{array}
$$

(b)

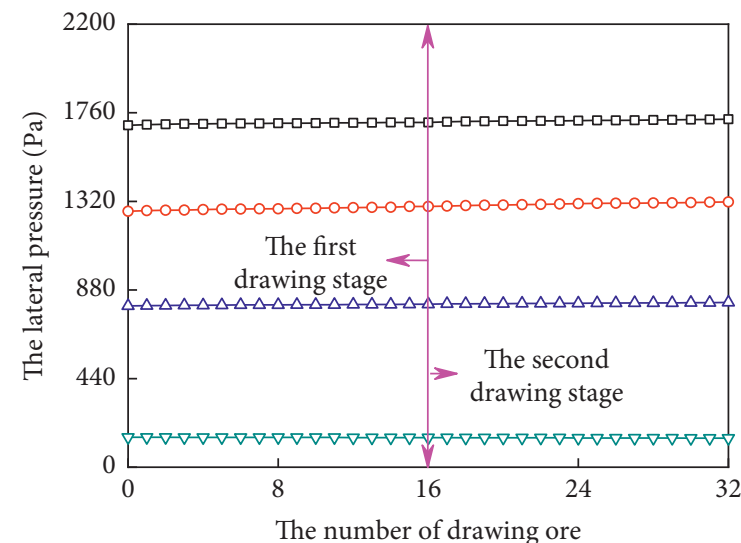

$$
\begin{array}{ll}
\longrightarrow-13 \#(h=0.65 \mathrm{~m}) & \rightarrow-15 \#(h=0.25 \mathrm{~m}) \\
\multimap-14 \#(h=0.45 \mathrm{~m}) & \rightarrow-16 \#(h=0.05 \mathrm{~m})
\end{array}
$$

(d)

FIGURE 4: The relationship between the number of drawing ore and the values of lateral pressure with scheme 1. 


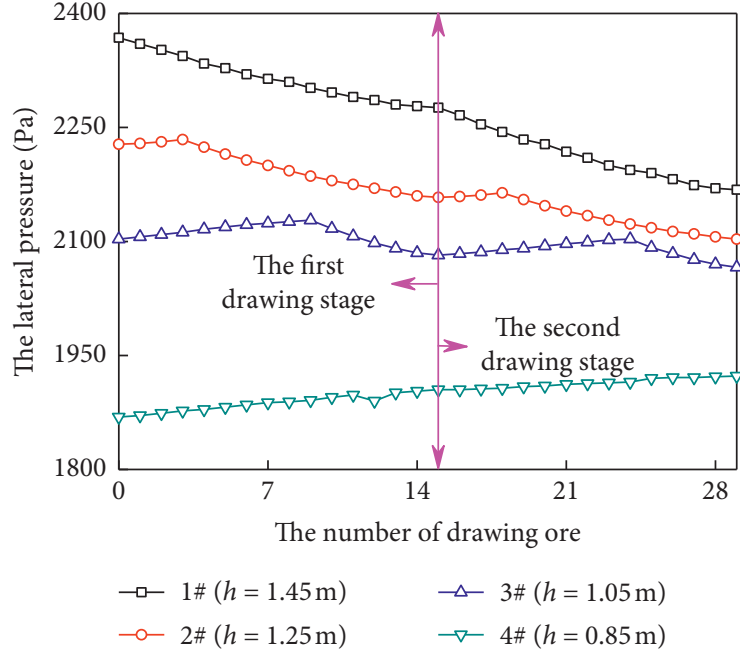

(a)

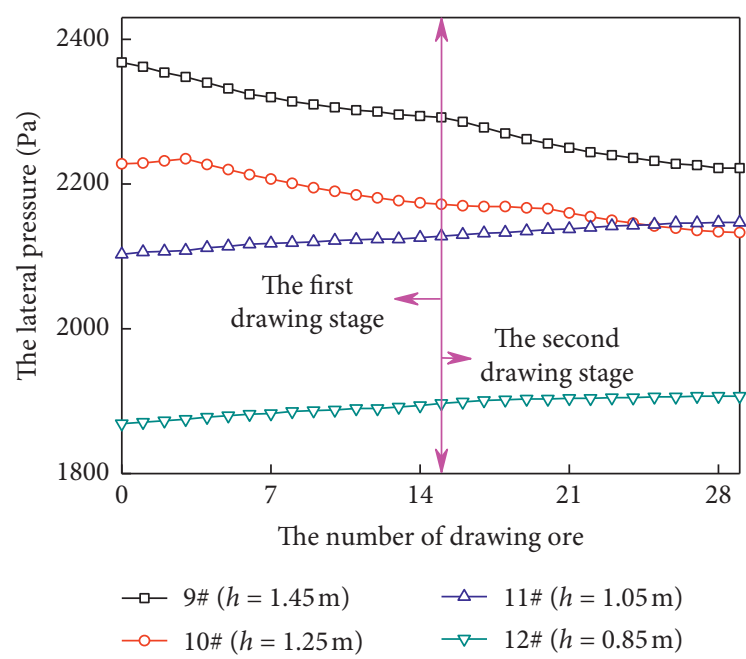

(c)

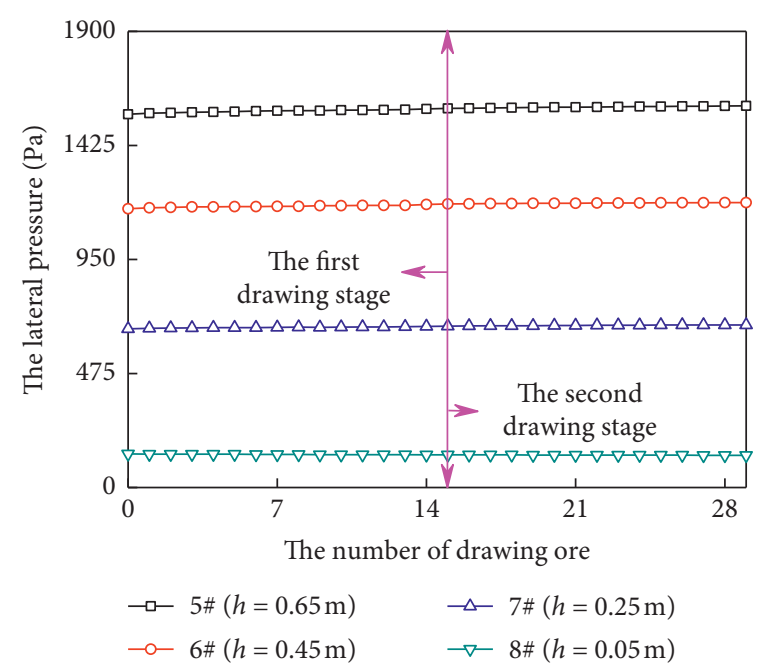

(b)

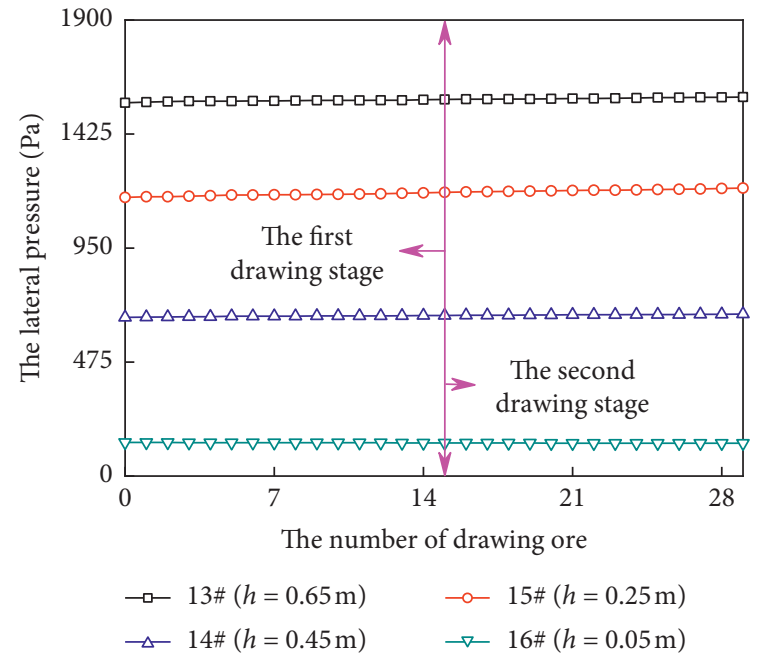

(d)

FIgURE 5: The relationship between the number of drawing ore and the values of lateral pressure with scheme 2.

drawing ore increased in the two drawing stages. Meanwhile, the lateral pressure of $8 \#$ and $16 \#$ test channels had a negative relationship with the number of drawing ore. The values of other test channels showed an increasing trend as the number of drawing ore rose.

In the drawing process, the scope of IEZ and isolated movement zone (IMZ) increased with an increase in number for drawing ore. Then, the granular media in the IMZ could be loosed, and that above the IMZ slowly collimation moved and the internal friction angle gradually increased. Hence, the lateral pressures were projected to continue decreasing while the test channels located in the scope of IME. Meanwhile, because of the relatively small scale of IMZ and increscent internal friction angle in the initial drawing phase, the measured values were augmented while the test channels above the scope of IMZ and then the lateral pressure descended as the IMZ reached the testing range of test channel. Due to the descending surface of granular media, the value of $8 \#$ and $16 \#$ test channels tended to gradual decline. As the nondilution ore drawing was used, the height of the IEZ and IMZ was about $30 \mathrm{~cm}$ and $73.8 \mathrm{~cm}$, respectively. Hence, the other values were expected to rise as the test channels were higher than $73.8 \mathrm{~cm}$.

The variation rates of lateral pressure under different stoping sequences and granular gradings are exhibited in Table 6. A new standpoint was proposed that the distribution laws could be divided into three parts. One part was drawing influencing region, which is located in the IMZ and had a positive relationship with the number of drawing ore. The other part was the upper descending zone, which is located in the surface of granular media and the volume was equal to the IEZ. The last part was central growth area, which was between the previous two parts. Then, the lateral pressure had a positive relationship with the number of drawing ore in the central growth area. As the number of drawing ore increased, the scope of drawing influencing region and upper descending zone increased, while the range of central growth area decreased. Moreover, the reduction rate of 

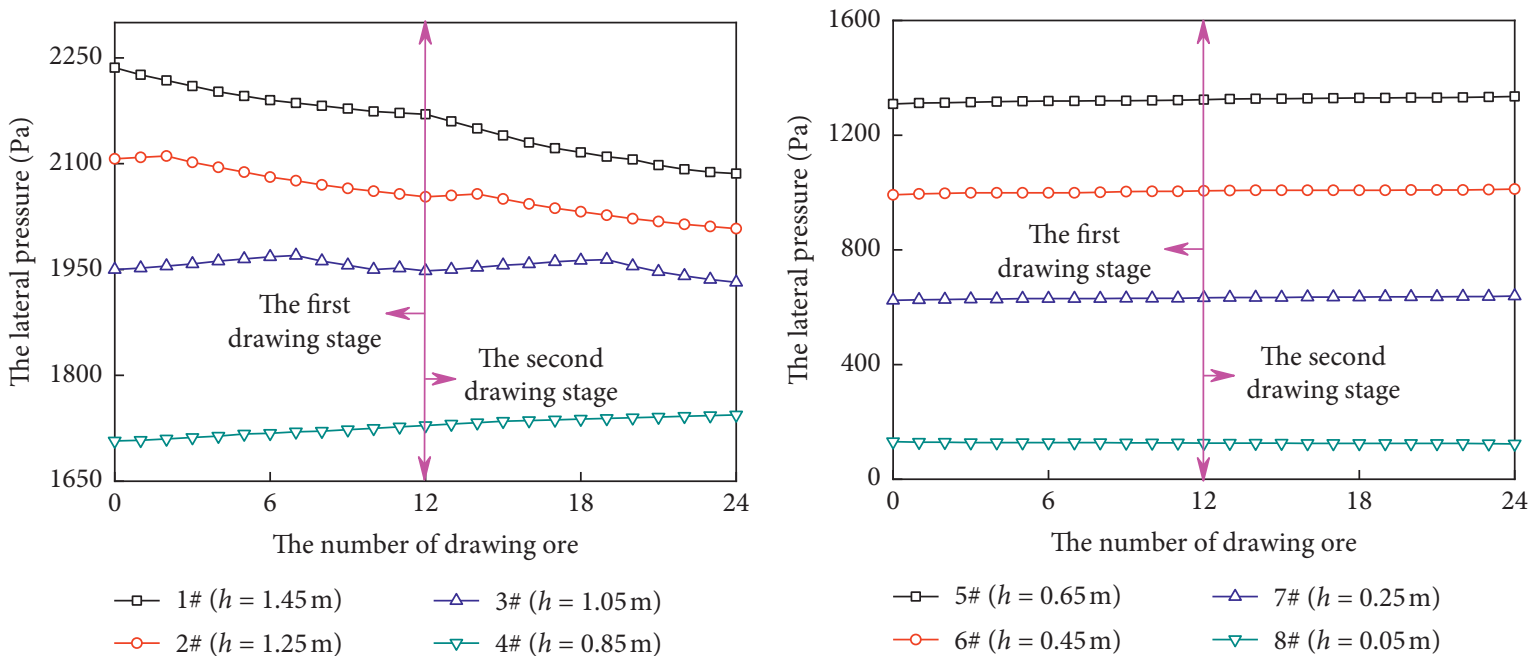

(a)

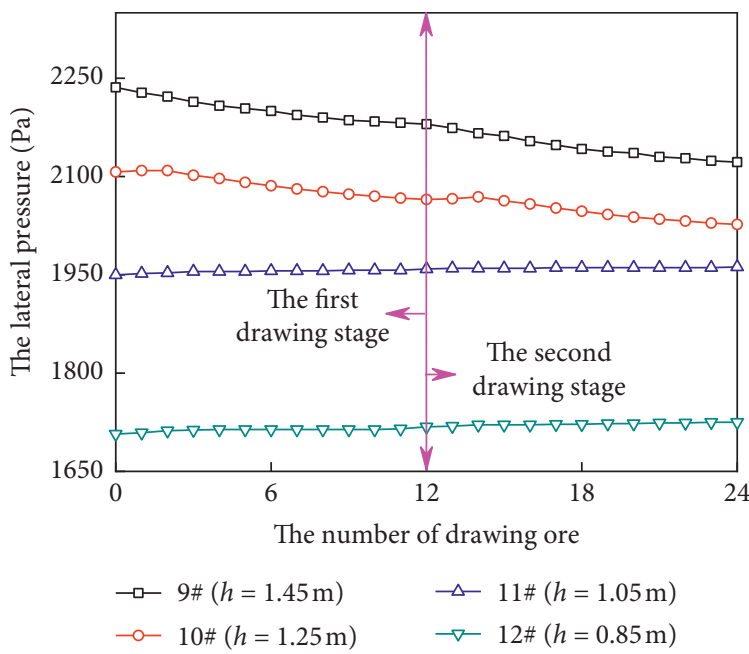

(c)

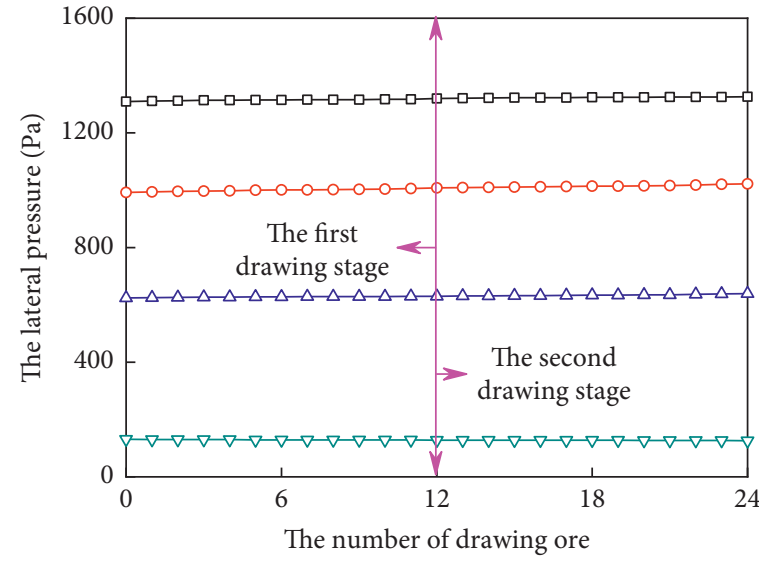

$\begin{array}{ll}\rightarrow-13 \#(h=0.65 \mathrm{~m}) & \rightarrow-15 \#(h=0.25 \mathrm{~m}) \\ \rightarrow-14 \#(h=0.45 \mathrm{~m}) & \rightarrow-16 \#(h=0.05 \mathrm{~m})\end{array}$

(d)

Figure 6: The relationship between the number of drawing ore and the values of lateral pressure with scheme 3.

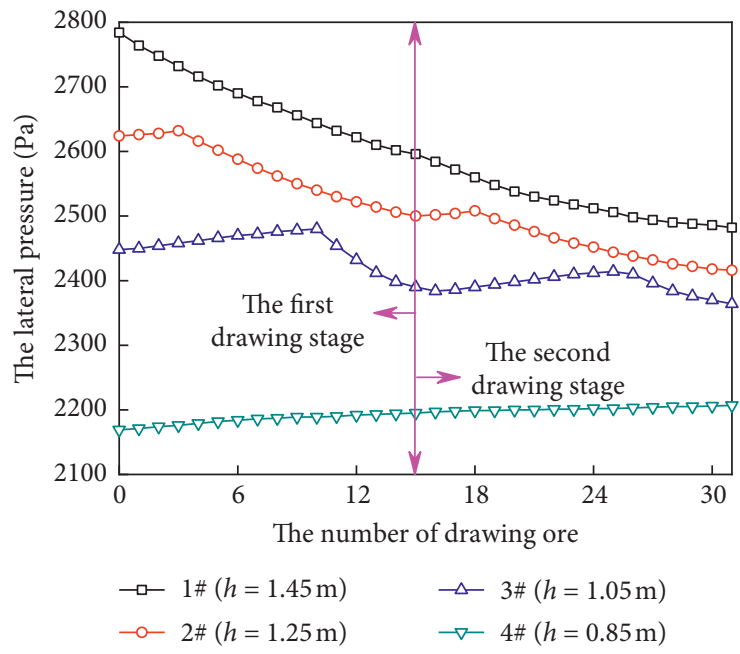

(a)

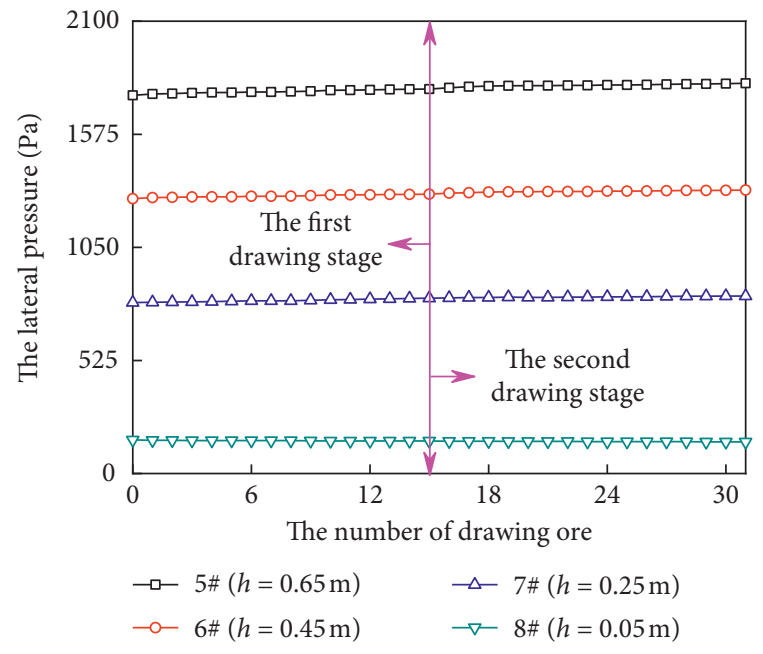

(b)

Figure 7: Continued. 


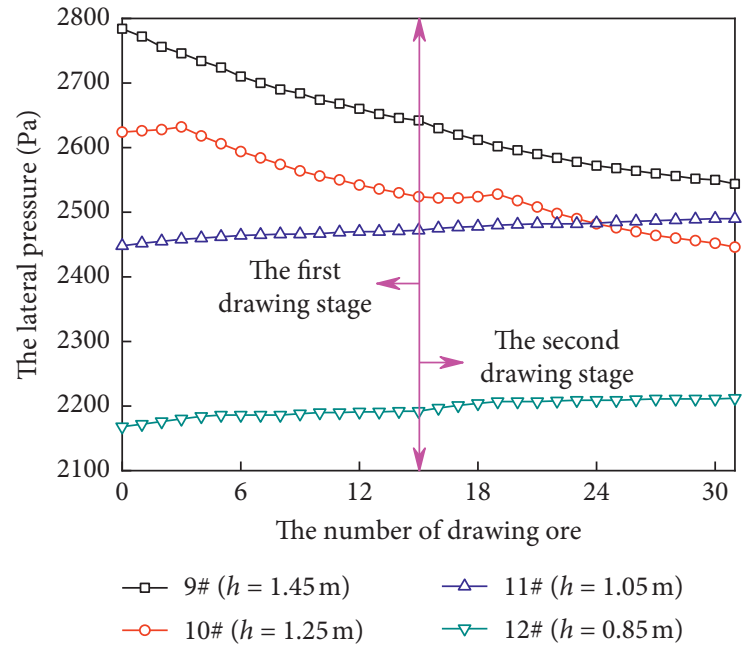

(c)

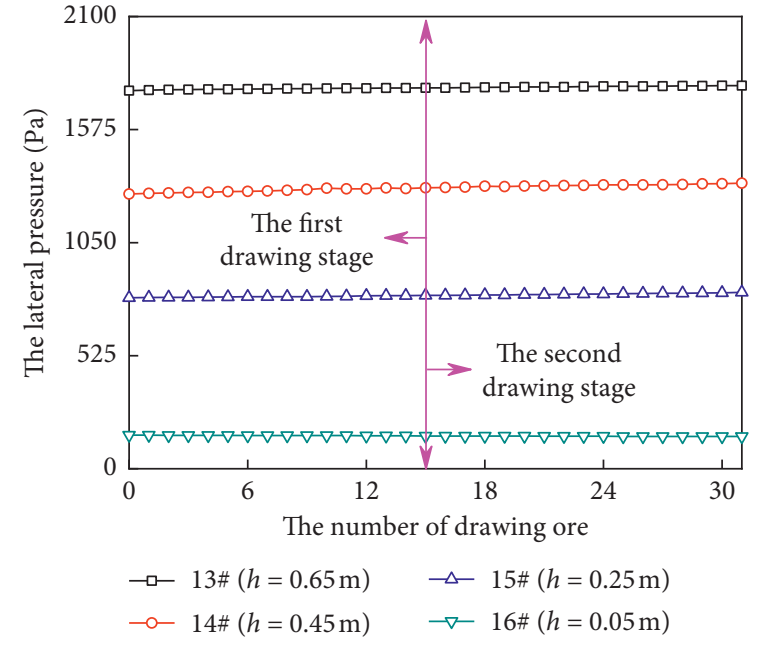

(d)

FIgURE 7: The relationship between the number of drawing ore and the values of lateral pressure with scheme 4.

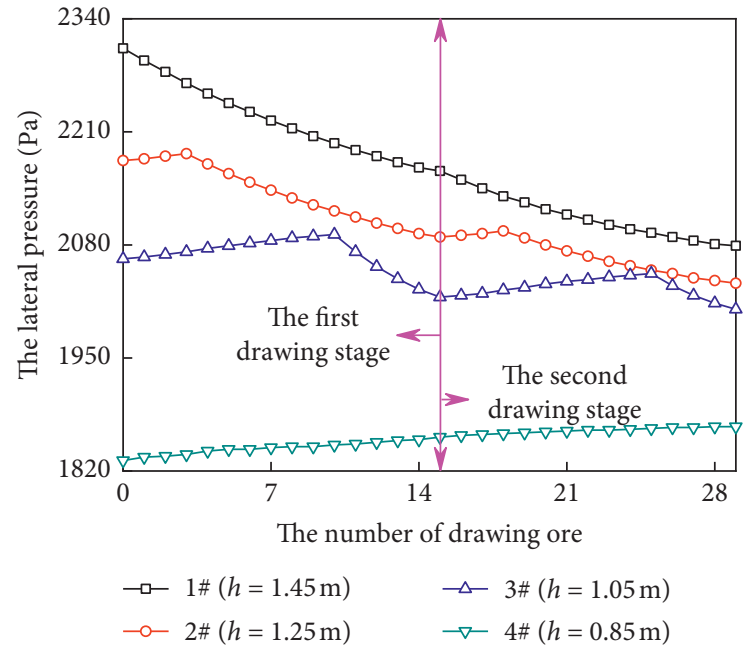

(a)

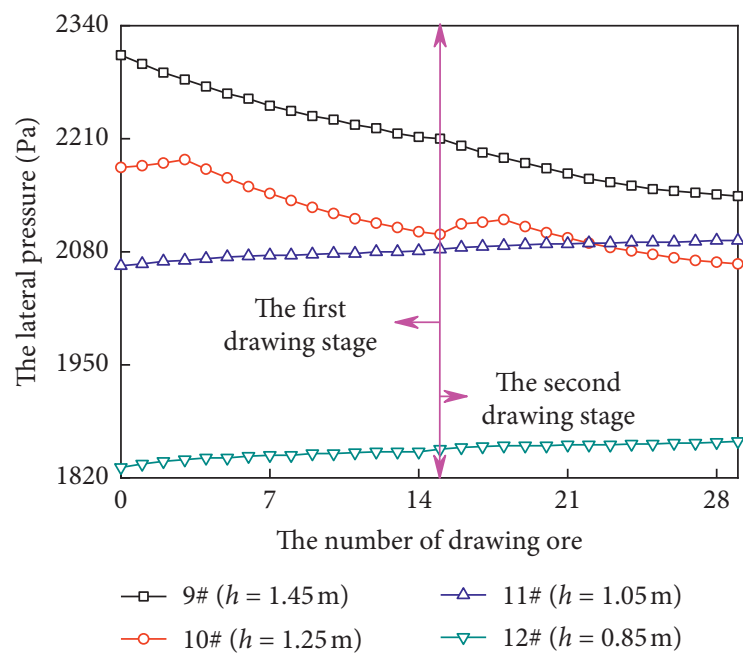

(c)

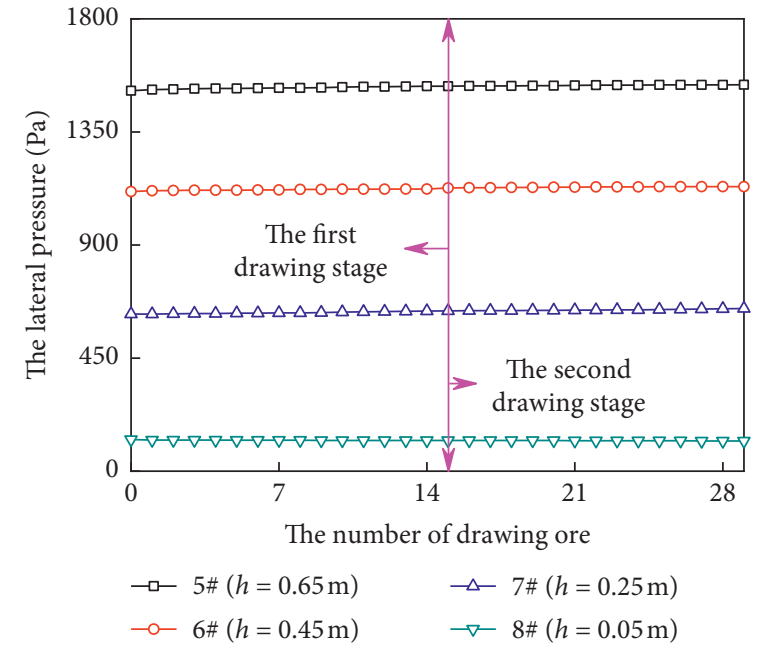

(b)

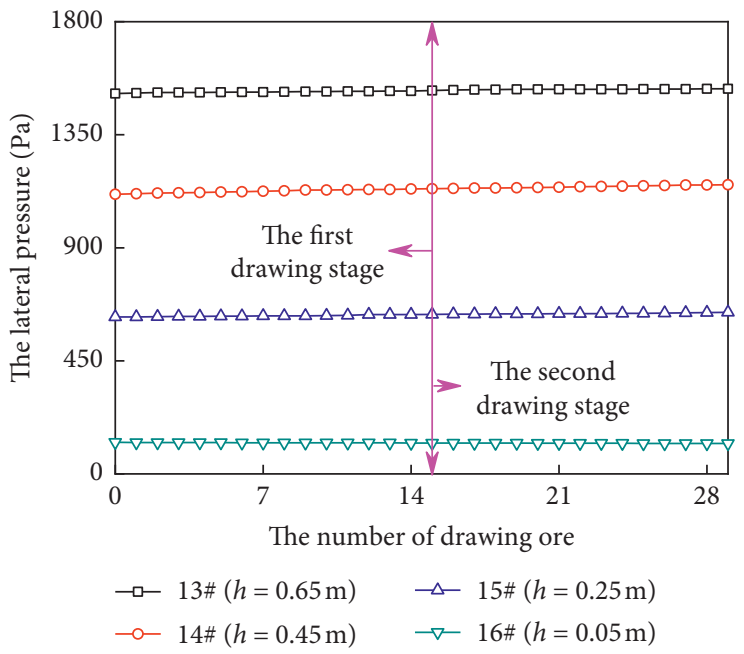

(d)

FIGURE 8: The relationship between the number of drawing ore and the values of lateral pressure with scheme 5. 


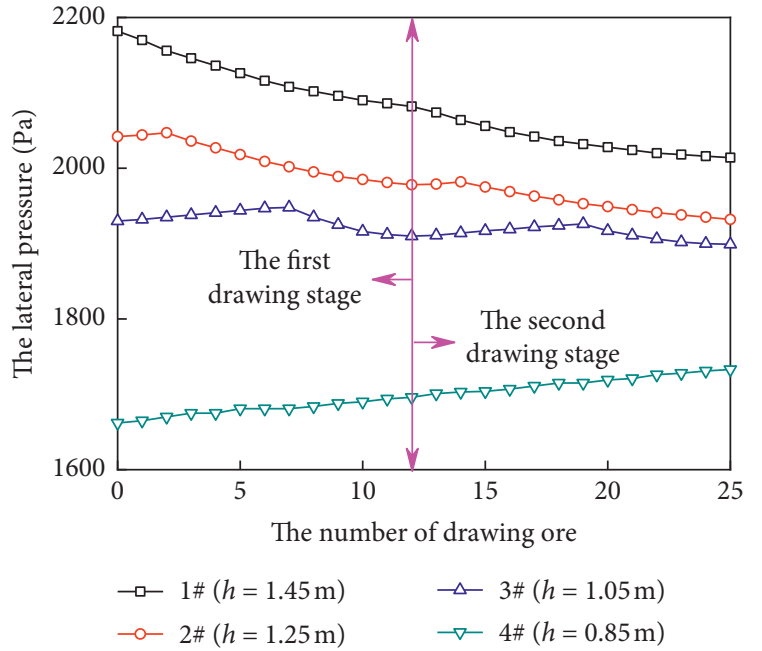

(a)

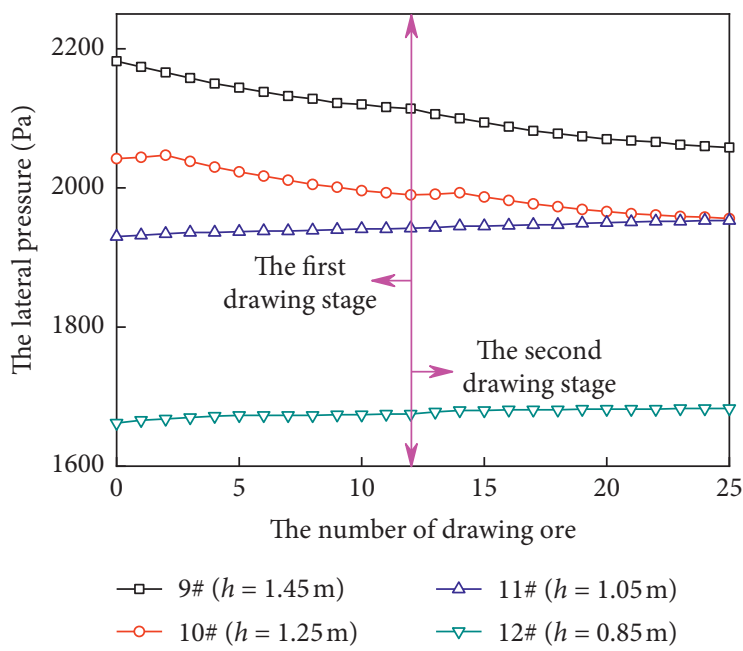

(c)

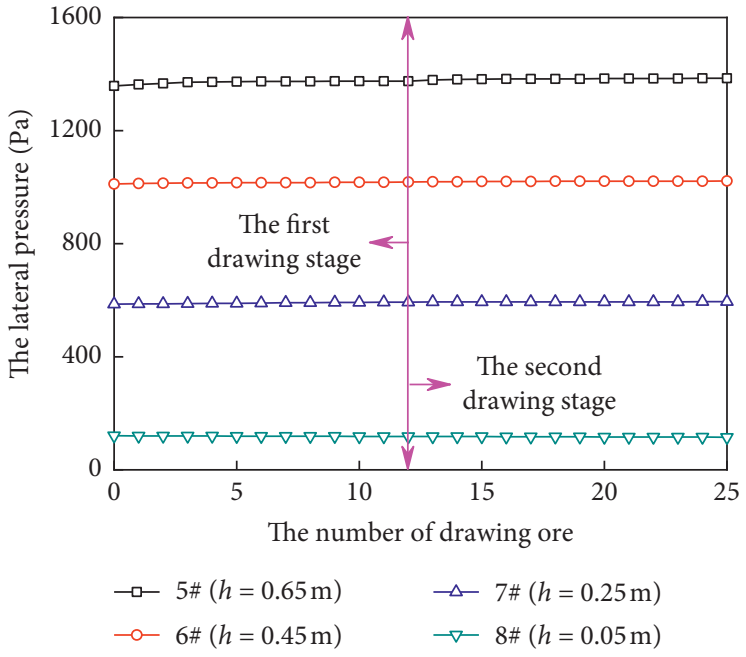

(b)

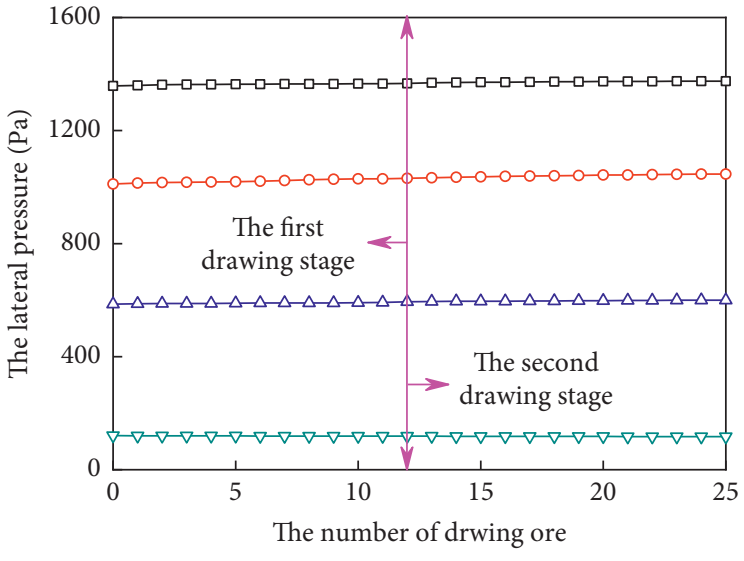

$$
\begin{aligned}
& \rightarrow \square \text { 13\# }(h=0.65 \mathrm{~m}) \quad \rightarrow-15 \#(h=0.25 \mathrm{~m}) \\
& \multimap-14 \#(h=0.45 \mathrm{~m}) \quad \rightarrow-16 \#(h=0.05 \mathrm{~m})
\end{aligned}
$$

(d)

FIGURE 9: The relationship between the number of drawing ore and the values of lateral pressure with scheme 6.

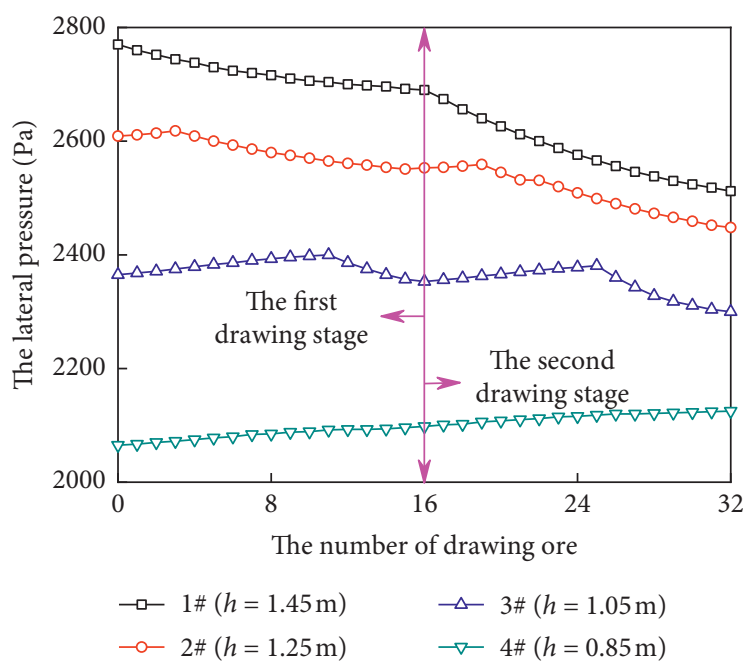

(a)

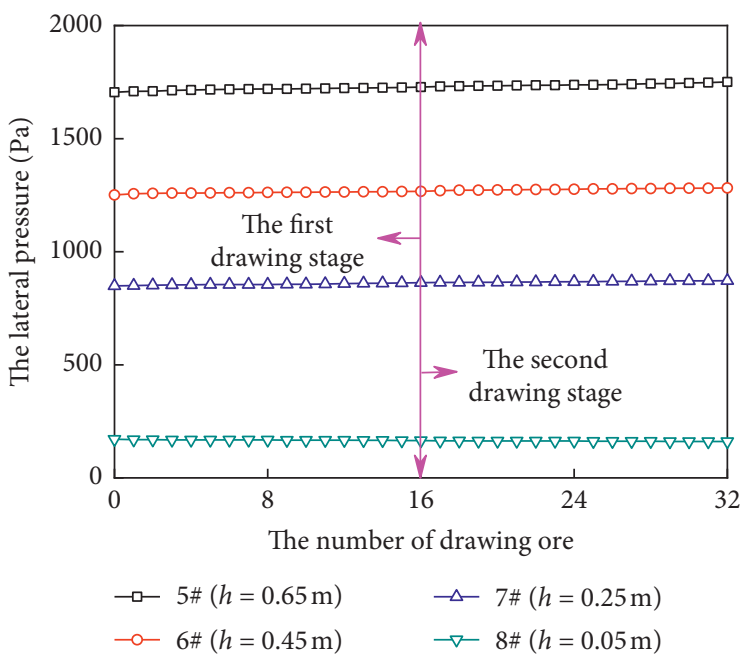

(b)

Figure 10: Continued. 


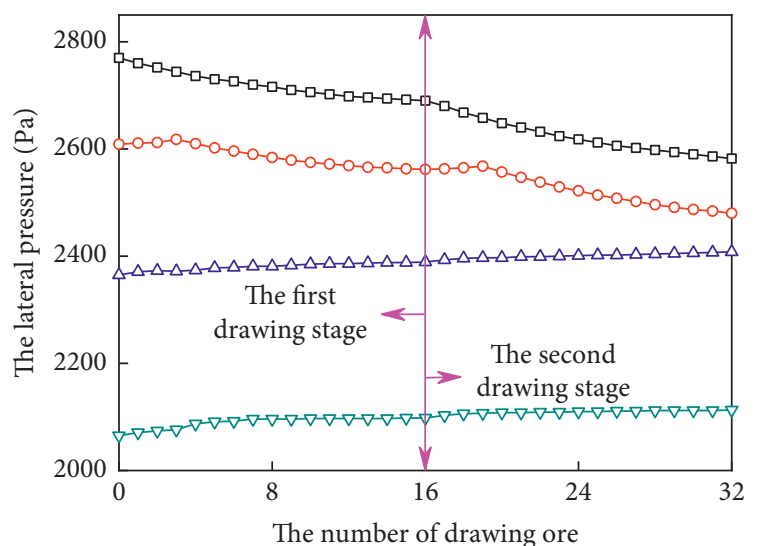

$$
\begin{array}{ll}
\rightarrow-9 \#(h=1.45 \mathrm{~m}) & \rightarrow-11 \#(h=1.05 \mathrm{~m}) \\
\rightarrow-10 \#(h=1.25 \mathrm{~m}) & \rightarrow-12 \#(h=0.85 \mathrm{~m})
\end{array}
$$

(c)

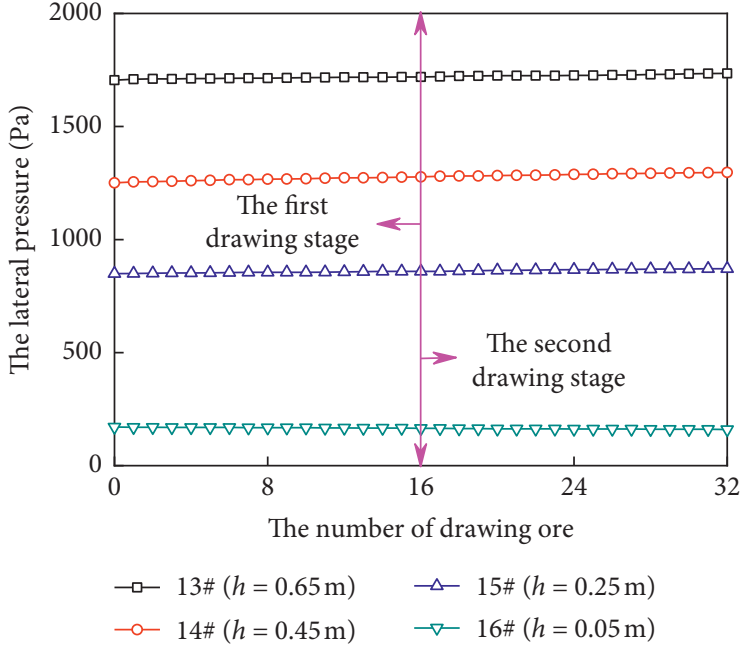

(d)

FIGURE 10: The relationship between the number of drawing ore and the values of lateral pressure with scheme 7 .
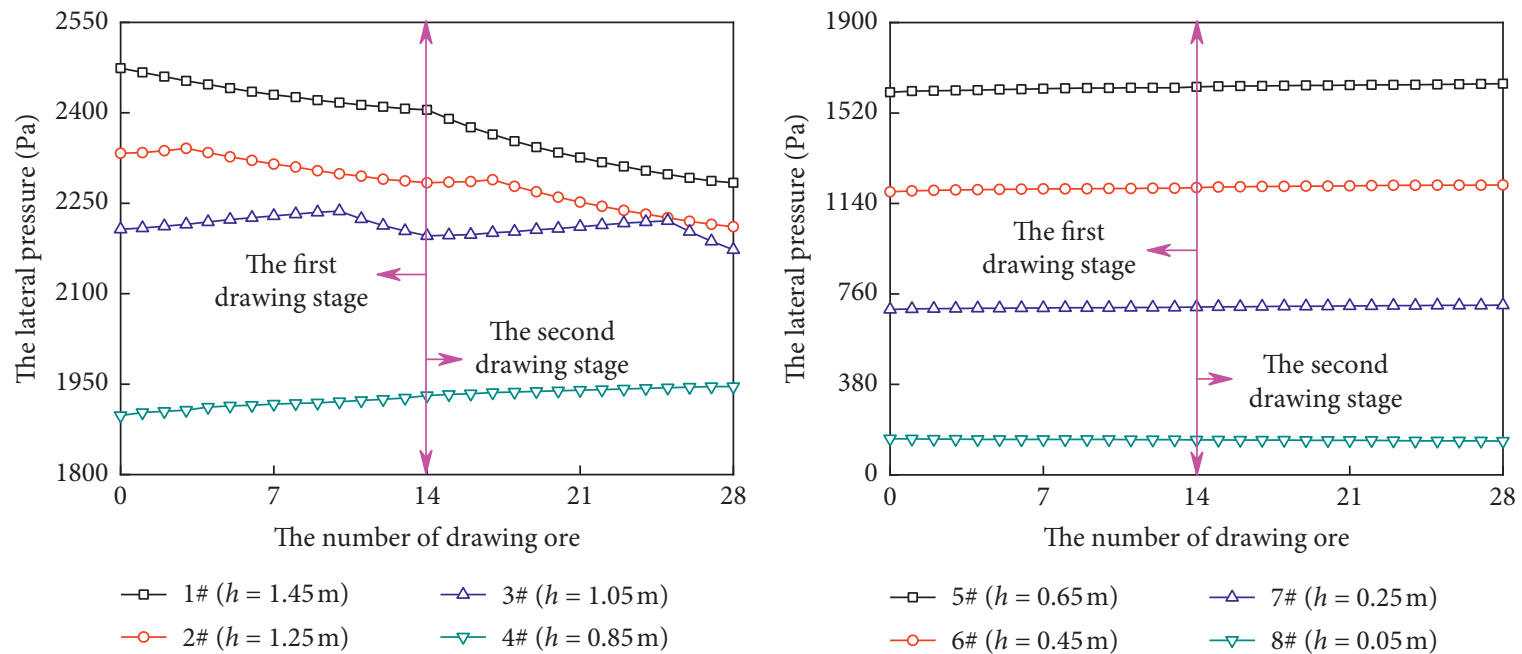

(a)

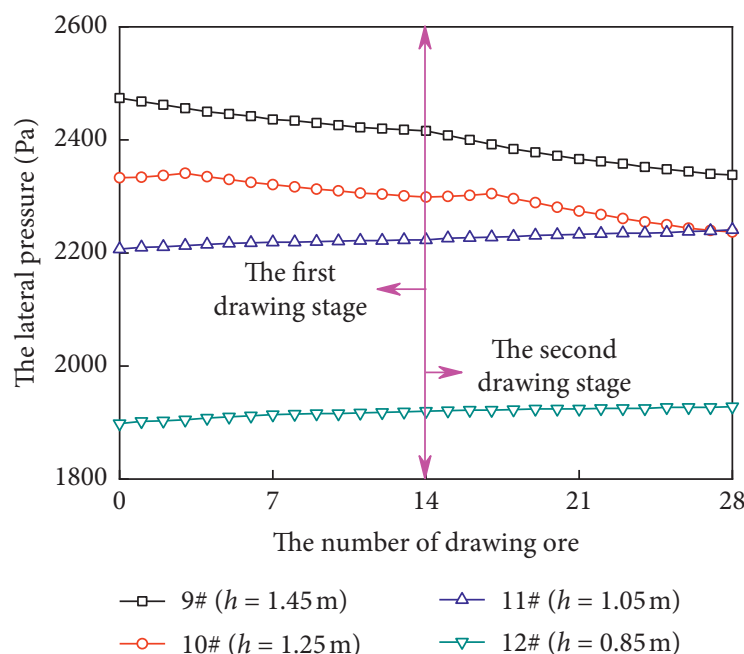

(c)

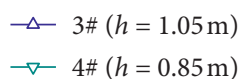

$\longrightarrow-1 \#(h=1.45 \mathrm{~m})$
$\multimap-2 \#(h=1.25 \mathrm{~m})$

$\rightarrow$ 4\# $(h=0.85 \mathrm{~m})$

$\multimap-6 \#(h=0.45 \mathrm{~m})$

(b)

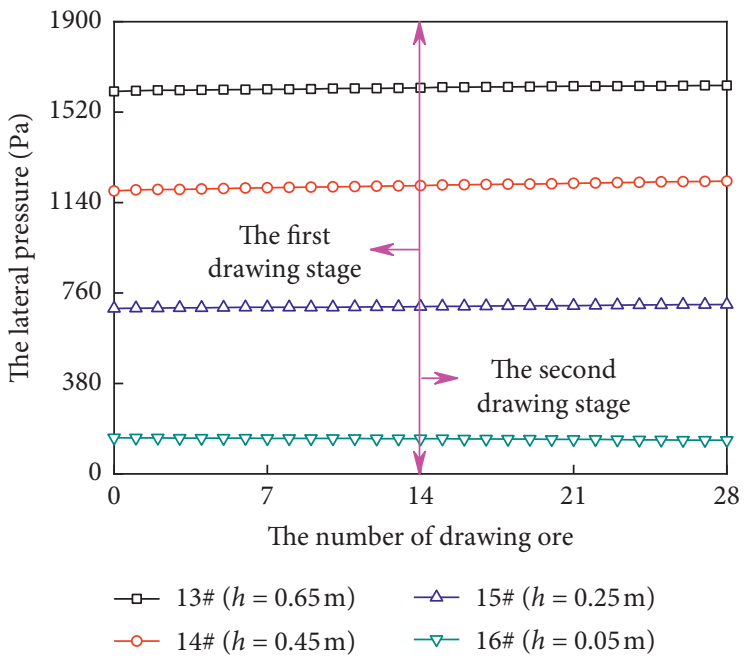

(d)

FIGURE 11: The relationship between the number of drawing ore and the values of lateral pressure with scheme 8 . 


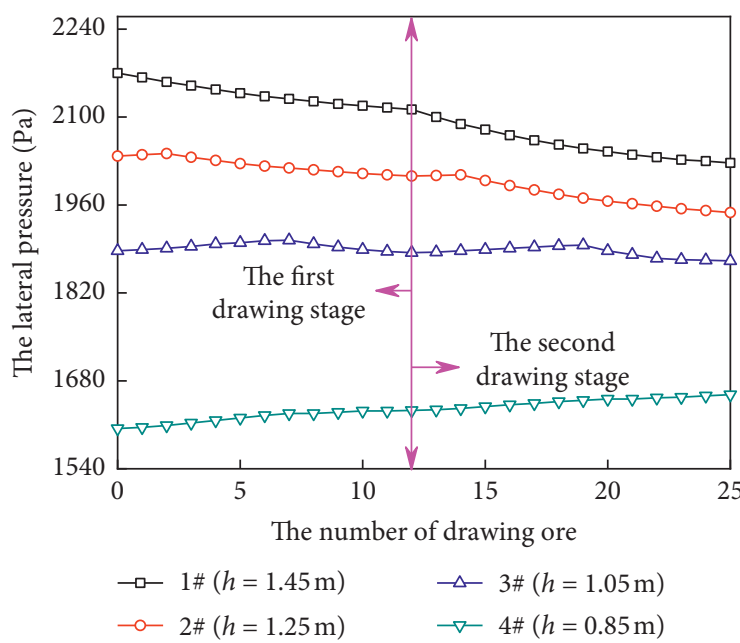

(a)

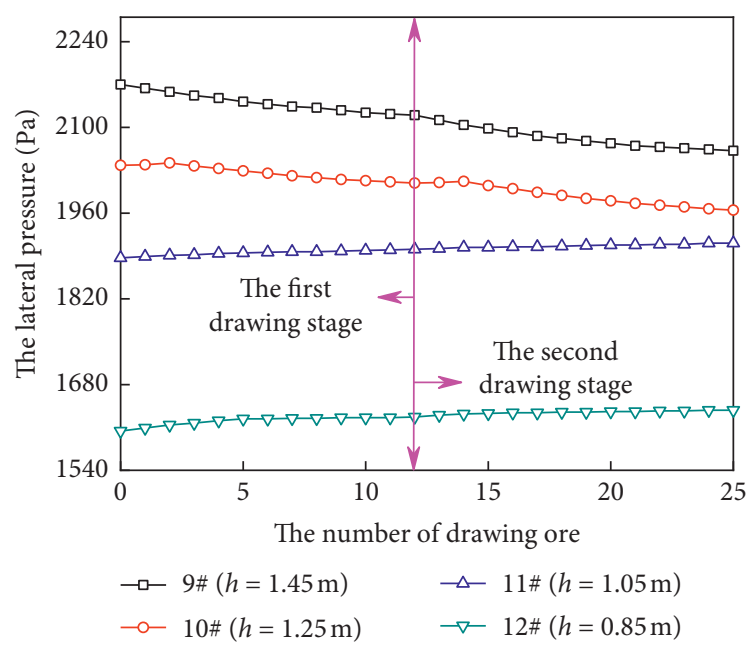

(c)

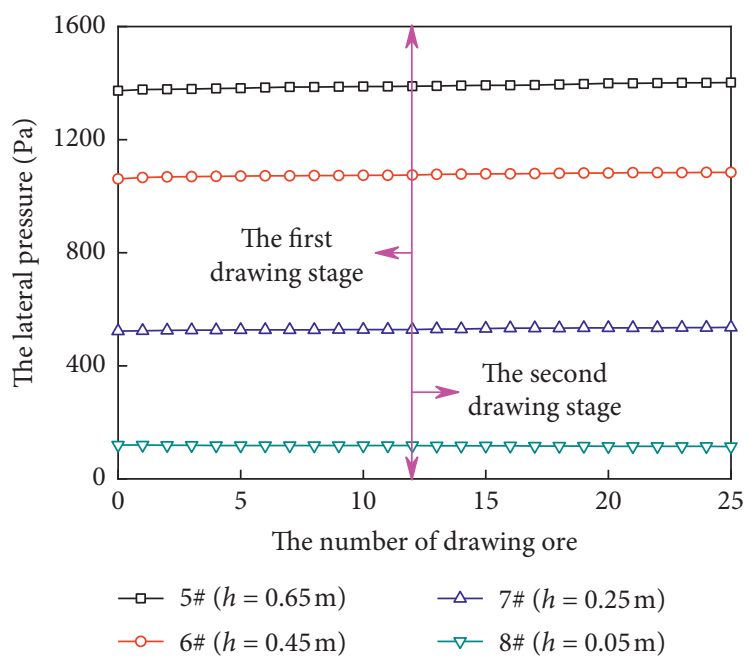

(b)

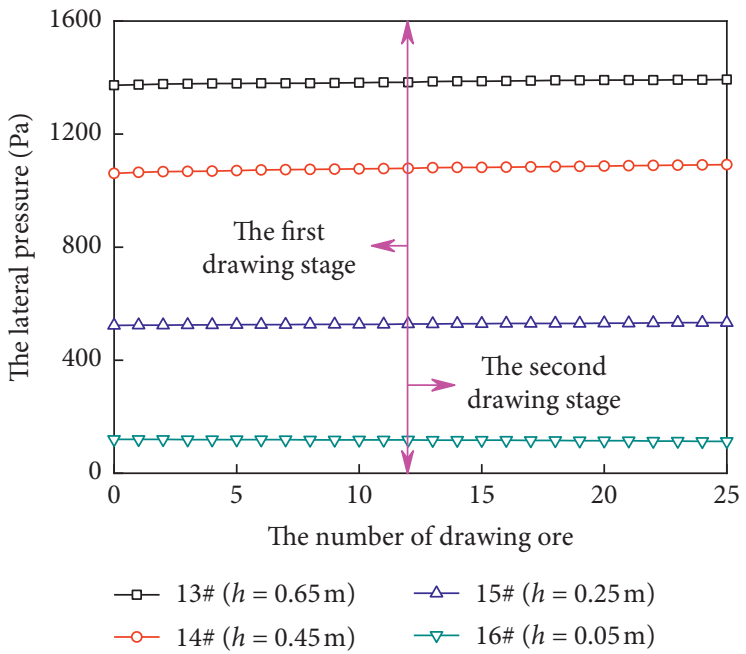

(d)

FIGURE 12: The relationship between the number of drawing ore and the values of lateral pressure with scheme 9.

lateral pressure showed a declining tendency as the height of granular media grew in the drawing influence region.

In the case of an invariable mining scheme and the same number of drawing ore, more reduction ratios and the scope for drawing influencing region could be appeared in the lower wall. Once the height and mass of the IEZ were identified, the scope of the drawing influencing region and the upper descending zone could be obtained and used to predict the range for the surface subsidence. Additionally, it was found that the stoping sequence and the granular grading both had a primary influence on the value of lateral pressure.

\subsection{The Relationship between Lateral Pressure and Stoping} Sequence. To convenient obtain the influencing effect of stoping sequences, the schemes were divided into three groups (group 1: scheme 1, scheme 2, and scheme 3; group 2: scheme 4, scheme 5, and scheme 6; and group 3: scheme 7, scheme 8, and scheme 9). The different stoping sequences would cause the changing of the granular grading after the first stage of drawing ore. Hence, the first stage of drawing ore in the same group was selected for studying the variation laws of lateral pressure influenced by stoping sequence so as to reduce the impact of granular grading, and the reduction rates of lateral pressure in the first stage for drawing ore are shown in Table 7. It could be noted that the scope of the three parts was unaffected by the stoping sequence, whereas the stoping sequence had an impact on the drawn mass at the same height of IEZ.

Meanwhile, the stoping sequence had a remarkable influence on the reduction rates of lateral pressure in the drawing influencing region. For the same granular grading and height of IEZ, more reduction rates of lateral pressure were observed with a decrease in the space between the drawpoints. For these three different stoping sequences (scheme 1 , scheme 4 , and scheme 7 ) with the same granular grading and height of IEZ $(30 \mathrm{~cm})$, the reductive rates of $1 \#$ and $9 \#$ test channels were $4.77 \%$ and $3.56 \%, 6.75 \%$ and $5.10 \%$, and $2.89 \%$ and $2.59 \%$, respectively, whereas the scope of drawing influencing region kept stable. 
TABLE 6: The variation rates of lateral pressure under different stoping sequences and granular gradings.

\begin{tabular}{|c|c|c|c|c|c|c|c|c|c|}
\hline \multirow{2}{*}{ Test channel } & \multicolumn{9}{|c|}{ Variation rates of lateral pressure (\%) } \\
\hline & Scheme 1 & Scheme 2 & Scheme 3 & Scheme 4 & Scheme 5 & Scheme 6 & Scheme 7 & Scheme 8 & Scheme 9 \\
\hline $1 \# h=1.45 \mathrm{~m}$ & -9.89 & -8.46 & -6.70 & -10.87 & -9.39 & -7.70 & -9.26 & -7.69 & -6.60 \\
\hline $2 \# h=1.25 \mathrm{~m}$ & -7.07 & -5.57 & -4.71 & -7.83 & -6.50 & -5.40 & -6.19 & -5.20 & -4.40 \\
\hline $3 \# h=1.05 \mathrm{~m}$ & -2.94 & -1.75 & -1.63 & -3.43 & -2.83 & -1.62 & -2.77 & -1.91 & -1.60 \\
\hline $4 \# h=0.85 \mathrm{~m}$ & 3.20 & 2.85 & 2.17 & 1.76 & 2.13 & 4.28 & 2.94 & 2.54 & 3.32 \\
\hline $5 \# h=0.65 \mathrm{~m}$ & 2.75 & 2.19 & 2.01 & 3.17 & 1.57 & 1.96 & 2.69 & 2.23 & 2.14 \\
\hline $6 \# h=0.45 \mathrm{~m}$ & 2.12 & 2.27 & 2.04 & 3.15 & 1.77 & 1.06 & 2.51 & 2.43 & 2.18 \\
\hline $7 \# h=0.25 \mathrm{~m}$ & 3.22 & 2.43 & 2.31 & 3.83 & 3.65 & 1.45 & 2.73 & 2.54 & 2.49 \\
\hline $8 \# h=0.05 \mathrm{~m}$ & -6.39 & -4.34 & -5.61 & -5.77 & -4.41 & -4.28 & -5.93 & -6.24 & -5.05 \\
\hline $9 \# h=1.45 \mathrm{~m}$ & -7.64 & -6.18 & -5.03 & -8.65 & -7.00 & -5.64 & -6.75 & -5.49 & -5.00 \\
\hline $10 \# h=1.25 \mathrm{~m}$ & -5.31 & -4.26 & -3.80 & -6.74 & -5.11 & -4.17 & -4.95 & -4.09 & -3.58 \\
\hline $11 \# h=1.05 \mathrm{~m}$ & 1.49 & 2.10 & 0.85 & 1.73 & 1.39 & 1.17 & 1.78 & 1.53 & 1.30 \\
\hline $12 \# h=0.85 \mathrm{~m}$ & 2.41 & 2.01 & 1.05 & 2.01 & 1.62 & 1.29 & 2.34 & 1.56 & 2.09 \\
\hline $13 \# h=0.65 \mathrm{~m}$ & 1.76 & 1.49 & 1.29 & 1.33 & 1.26 & 1.26 & 1.79 & 1.58 & 1.49 \\
\hline $14 \# h=0.45 \mathrm{~m}$ & 3.62 & 3.28 & 3.07 & 3.95 & 3.47 & 3.48 & 3.63 & 3.49 & 2.88 \\
\hline $15 \# h=0.25 \mathrm{~m}$ & 2.08 & 2.01 & 2.29 & 3.10 & 2.88 & 2.41 & 2.66 & 2.49 & 2.03 \\
\hline $16 \# h=0.05 \mathrm{~m}$ & -3.49 & -2.47 & -3.9 & -4.0 & -3.97 & -3.16 & -6.20 & -6.78 & -6.40 \\
\hline
\end{tabular}

TABLE 7: The reduction rates of lateral pressure in the first stage for drawing ore.

\begin{tabular}{|c|c|c|c|c|c|c|}
\hline \multirow{2}{*}{ Group } & \multirow{2}{*}{ Scheme } & \multicolumn{5}{|c|}{ The variation rates of lateral pressure (\%) } \\
\hline & & $1 \# h=1.45 \mathrm{~m}$ & $2 \# h=1.25 \mathrm{~m}$ & $3 \# h=1.05 \mathrm{~m}$ & $9 \# h=1.45 \mathrm{~m}$ & $10 \# h=1.25 \mathrm{~m}$ \\
\hline \multirow{3}{*}{1} & 1 & -4.77 & -3.94 & -1.32 & -3.56 & -3.12 \\
\hline & 4 & -6.75 & -4.72 & -2.37 & -5.10 & -3.81 \\
\hline & 7 & -2.89 & -2.15 & -0.84 & -2.59 & -1.82 \\
\hline \multirow{3}{*}{2} & 2 & -3.89 & -3.14 & -1.03 & -3.21 & -2.52 \\
\hline & 5 & -6.12 & -4.04 & -2.16 & -4.16 & -3.55 \\
\hline & 8 & -2.82 & -2.10 & -0.80 & -2.34 & -1.42 \\
\hline \multirow{3}{*}{3} & 3 & -2.95 & -2.55 & -0.86 & -2.61 & -2.02 \\
\hline & 6 & -4.58 & -3.18 & -1.08 & -3.12 & -2.57 \\
\hline & 9 & -2.67 & -1.59 & -0.74 & -2.30 & -1.44 \\
\hline
\end{tabular}

4.4. The Relationship between Lateral Pressure and Granular Grading. To obtain the effect of granular grading, the different mining schemes were divided into three groups (group 1: scheme 1, scheme 4, and scheme 7; group 2: scheme 2, scheme 5, and scheme 8; group 3: scheme 3, scheme 6, and scheme 9), and the relationships between the granular grading and lateral pressure of reduction rates and average values are shown in Table 8 . With an increase in the granular grading, the scope of the drawing influencing region had no significant decrease, whereas the mass drawn from the drawpoints decreased. Additionally, it was found that the granular grading had a primary influence on the variation rate of lateral pressure, in which the reduction rate and reductive ratio in the drawing influencing region were inconsistent with each other in same stoping sequence, and the reduction rate had a negative relationship with the granular grading. With the same stoping sequence and height of IEZ, the average values of lateral pressure increased as the granular grading decreased at the same height of granular media. Because of the more mobility and unit weight of granular media, which were generated from the more uniform and smaller size of the granular, the more reductive rate and average values of lateral pressure were obtained. For three granular gradings (scheme 4, scheme 5, and scheme 6) with the height of IEZ of $30 \mathrm{~cm}$ and the same stoping sequence, the reduction rates of $1 \#$ and $9 \#$ test channels were $10.87 \%$ and $8.65 \%, 9.39 \%$ and $7.00 \%$, and $7.70 \%$ and $5.64 \%$, respectively, and the average values of the lower wall and upper wall were $1696 \mathrm{~Pa}$ and $1720 \mathrm{~Pa}, 1428 \mathrm{~Pa}$ and $1452 \mathrm{~Pa}$, and $1336 \mathrm{~Pa}$ and $1348 \mathrm{~Pa}$, respectively.

\section{Discussion}

In this study, the stoping sequence and granular grading were chosen as the main influencing factors on the distribution laws of lateral pressure induced by nonpillar sublevel caving mining. For calculating the lateral pressure, its success mainly depended on the stoping sequence, granular grading, the properties of granular media, and structural parameters. For instance, in terms of the layout of the sublevel parameters used in this test, the bigger the height of sublevel was, the bigger the shape of IEZ at the same stoping sequence and granular grading, and therefore bigger range of drawing influencing region and reductive rate of lateral pressure that would correspondingly be appeared.

Research on the variation laws of lateral pressure played an important role in predicting the scope of surface subsidence for theoretical and practical guidance in mine 
TABLE 8: The relationship between the granular grading and lateral pressure of reduction rates and average values.

\begin{tabular}{|c|c|c|c|c|c|c|c|c|}
\hline \multirow[t]{2}{*}{ Group } & \multirow[t]{2}{*}{ Scheme } & \multicolumn{5}{|c|}{ The variation rates of lateral pressure (\%) } & \multicolumn{2}{|c|}{$\begin{array}{c}\text { The average values of lateral } \\
\text { pressure }(\mathrm{Pa})\end{array}$} \\
\hline & & $1 \# h=1.45 \mathrm{~m}$ & $2 \# h=1.25 \mathrm{~m}$ & $3 \# h=1.05 \mathrm{~m}$ & $9 \# h=1.45 \mathrm{~m}$ & $10 \# h=1.25 \mathrm{~m}$ & The lower wall & The upper wall \\
\hline \multirow{3}{*}{1} & 1 & -9.89 & -7.07 & -2.94 & -7.64 & -5.31 & 1638 & 1662 \\
\hline & 2 & -8.46 & -5.57 & -1.75 & -6.18 & -4.26 & 1482 & 1500 \\
\hline & 3 & -6.70 & -4.71 & -1.63 & -5.03 & -3.80 & 1360 & 1368 \\
\hline \multirow{3}{*}{2} & 4 & -10.87 & -7.83 & -3.43 & -8.65 & -6.74 & 1696 & 1720 \\
\hline & 5 & -9.39 & -6.50 & -2.83 & -7.00 & -5.11 & 1428 & 1452 \\
\hline & 6 & -7.70 & -5.40 & -1.62 & -5.64 & -4.17 & 1336 & 1348 \\
\hline \multirow{3}{*}{3} & 7 & -9.26 & -6.19 & -2.77 & -6.75 & -4.95 & 1682 & 1962 \\
\hline & 8 & -7.69 & -5.20 & -1.91 & -5.49 & -4.09 & 1542 & 1558 \\
\hline & 9 & -6.60 & -4.40 & -1.60 & -5.00 & -3.58 & 1330 & 1338 \\
\hline
\end{tabular}

production. The main characteristics of the reductive rate and the variation laws for lateral pressure could be referenced to propose a method for predicting the failure condition of rock mass, as well as deeply analyzing the mechanisms of rock movement and determining the stoping parameters. For instance, Li et al. tried to predict the range of surface subsidence induced by the nonpillar sublevel caving mining [5]. The distribution laws of lateral pressure were the foundation of constructing a correct predicting calculation since the laws intensively reflected the stress characteristics of rock mass in the caved rock zone.

In this study, a new standpoint was proposed that the distribution laws could be divided into three parts, and then the lateral pressure increased exponentially with increasing depth of granular media. Ren et al. [35] and He et al. [36] reported the distribution laws of lateral pressure from different orebody dip conditions, which seemed consistent with the scope of drawing influencing region, but to a certain extent had its variation on the upper descending zone and the central growth area. These abovementioned results are under the invariable width of orebody, and the vibration of blasting is not considered; further studies are essential to improve this simple description to the more comprehensive results of complex gravity flow encountered in actual mines. In addition, certain parameters, such as the width and dip of orebody, the size of drawpoint, the properties of granular media and the shape of wall side, could be considered and studied using a 3D physical model or in situ experiments.

\section{Conclusions}

In this study, a laboratory-scaled physical model was designed to investigate the influence of stoping sequence and granular grading on the lateral pressure during the drawing process. Under the limiting equilibrium state, the values of lateral pressure increased exponentially with the increasing depth of granular media, and the growth rate of lateral pressure gradually decreased as the depth of granular media increased. Meanwhile, the experimental results showed that the distribution laws of lateral pressure were divided into three parts including the drawing influencing region, the upper descending zone, and the central growth area. The shape of three parts was virtually identified under different stoping sequences and granular gradings. In addition, the mass drawn or the height of the IEZ could increase the scope of drawing influencing region and upper descending zone and could reduce the range of the central growth area. For the same height of IEZ, more reduction ratio and the scope for drawing influencing region could be appeared in the lower wall. Then, the influencing laws of granular grading and stoping sequence on the reduction rates of drawing influencing region complemented each other. The reduction rates in the drawing influencing region showed an increasing trend as the interval of drawpoint and granular grading decreased, and the scope of these parts was negligibly affected by the stoping sequence and granular grading. Moreover, the average values of lateral pressure increased with a decrease in the size of granular media as the height of the IEZ and stoping sequence remain constant.

The experimental results could help to understand the distribution laws of lateral pressure under stoping sequence and granular grading and provided an experimental tool to predict the range of surface subsidence.

\section{Data Availability}

The data used to support the findings of this study are available from the corresponding author upon request.

\section{Conflicts of Interest}

The authors declare that they have no conflicts of interest.

\section{Acknowledgments}

This work was supported by the Key Program of the National Natural Science Foundation of China (no. 51534003), the National Basic Research Program of China (no. 2016YFC0801601), and the Fundamental Research Funds for the Central Universities (no. N150104006).

\section{References}

[1] H. Liu, P. Peng, and L. Wang, "Comprehensive evaluation and simulation for large-scale mining using natural caving method," Journal of Central South University, vol. 46, no. 2, pp. 617-624, 2015.

[2] A. Jin, H. Sun, G. Ma, Y. Gao, S. Wu, and X. Meng, "A study on the draw laws of caved ore and rock using the discrete 
element method," Computers and Geotechnics, vol. 80, pp. 59-70, 2016.

[3] L. C. Li, C. A. Tang, X. D. Zhao, and M. Cai, "Block cavinginduced strata movement and associated surface subsidence: a numerical study based on a demonstration model," Bulletin of Engineering Geology and the Environment, vol. 73, no. 4, pp. 1165-1182, 2014.

[4] Y. Wang, Technologies for Coordinated Mining of Open-Pit and Underground Mining at Southeastern of Gongchangling Iron Mine, Northeastern University, Shenyang, China, 2013, in Chinese.

[5] H. Y. Li, F. Y. Ren, X. Y. Chen, and G. H. Gong, "The method for predicting and controlling the range of surface subsidence during deep ore-body mining," Journal of Northeastern University (Natural Science), vol. 33, no. 11, pp. 1624-1627, 2012, in Chinese.

[6] D. L. Song, F. Y. Ren, J. D. Qi, and M. L. Dou, "Delineation optimization of incline shaft safety pillar for North mining area of Xishimen iron," Metal Mine, vol. 45, no. 4, pp. 13-15, 2016, in Chinese.

[7] E. T. Brown and G. A. Ferguson, "Progressive hanging wall caving, Gath's mine, Rhodesia," Trans Inst Min Metall, vol. 88, pp. A92-A105, 1979.

[8] J. R. Jahanson, "The use of flow-corrective inserts in bins," Journal of Engineering for Industry, vol. 88, no. 2, pp. 224-230, 1966.

[9] A. W. Jenike, Storage and Flow of Solids, Bulletin of the Utah Engineering Experiment, 1980.

[10] D. M. Walker, "An approximate theory for pressures and arching in hoppers," Chemical Engineering Science, vol. 21, no. 11, pp. 975-997, 1966.

[11] J. K. Walters, "A theoretical analysis of stresses in silos with vertical walls," Chemical Engineering Science, vol. 28, no. 1, pp. 13-21, 1973.

[12] P. Karasudhi, Foundations of Solid Mechanics, Kluwer Academic Publishers, Dordrecht, Netherlands, 1965.

[13] M. Sperl, "Experiments on corn pressure in silo cells translation and comment of Janssen's paper from 1895," Granular Matter, vol. 8, no. 2, pp. 59-65, 2006.

[14] M. Reimbert and A. Reimbert, "Pressure and overpressure vertical and horizontal silos," in Proceedings of the International Conference Design of Silos for Strength and Flow, Powder Advisory Cent London, England, UK, 1980.

[15] M. Ichihara and H. Matsuzawa, "Earth pressure during earthquake," Soils and Foundations, vol. 13, no. 4, pp. 75-86, 1973.

[16] W. Airy, “The pressure of grain," Minutes of Proceedings, Institution of Civil Engineers, vol. 13, no. 1, pp. 347-358, 1987.

[17] X. S. Chen, "Extension of classical Janssen loose mass pressure theory and its application in mining engineering," Chinese Journal of Geotechnical Engineering, vol. 32, no. 2, pp. 315319, 2010, in Chinese.

[18] D. Li, Study of Lateral Pressure Mechanism between Granular and Bin of Heavy Vehicle, Tianjin University, Tianjing, China, 2014, in Chinese.

[19] A. W. Jenike, "A theory of flow of particulate solids in converging and diverging channels based on a conical yield function," Powder Technology, vol. 50, no. 3, pp. 229-236, 1987.

[20] C. J. Brown, E. H. Lahlouh, and J. M. Rotter, "Experiments on a square planform steel silo," Chemical Engineering Science, vol. 55, no. 20, pp. 4399-4413, 2000.

[21] L. Yang, F. Y. Ren, R. X. He, and J. L. Cao, "Prediction of surface subsidence range based on the critical medium column's theory under ore drawing," Journal of Northeastern University (Natural Science), vol. 39, no. 3, pp. 416-420, 2018, in Chinese.

[22] P. Vidal, A. Couto, F. Ayuga, and M. Guaita, "Influence of Hopper eccentricity on discharge of cylindrical mass flow silos with rigid walls," Journal of Engineering Mechanics, vol. 132, no. 9, pp. 1026-1033, 2006.

[23] M. Guaita, A. Couto, and F. Ayuga, "Numerical simulation of wall pressure during discharge of granular material from cylindrical silos with eccentric hoppers," Biosystems Engineering, vol. 85, no. 1, pp. 101-109, 2003.

[24] M. H. Sadd, G. Adhikari, and F. Cardoso, "DEM simulation of wave propagation in granular materials," Powder Technology, vol. 109 , no. $1-3$, pp. 222-233, 2000.

[25] W. C. Paul, "DEM simulation of industrial particle flows: case studies of dragline excavators, mixing in tumblers and centrifugal mills," Powder Technology, vol. 109, no. 1, pp. 83-104, 2000.

[26] S. Bock and S. Prusek, "Numerical study of pressure on dams in a backfilled mining shaft based on PFC3D code," Computers and Geotechnics, vol. 66, pp. 230-244, 2015.

[27] H. M. Zhen, X. W. Wang, and Z. J. Yang, "Distinct element simulation on lateral pressure during coal discharging process of coal silo based on PFC3D," Coal Engineering, vol. S1, pp. 123-125, 2013, in Chinese.

[28] J. B. Fu, Limit Analysis and Elastio-Plastic Finite Element Analysis of Lateral Pressure of Large Silo under Complicated Conditions, Dalian University of Technology, Dalian, China, 2013, in Chinese.

[29] K. V. Kuzmin and A. V. Baranov, "Principles of research of mining method of uncontrolled ore caving by physical simulation," Radio Science, vol. 31, no. 2, pp. 245-261, 2009.

[30] F. Melo, F. Vivanco, and C. Fuentes, "Calculated isolated extracted and movement zones compared to scaled models for block caving," International Journal of Rock Mechanics and Mining Sciences, vol. 46, no. 4, pp. 731-737, 2009.

[31] R. Castro, R. Trueman, and A. Halim, "A study of isolated draw zones in block caving mines by means of a large $3 \mathrm{D}$ physical model," International Journal of Rock Mechanics and Mining Sciences, vol. 44, no. 6, pp. 860-870, 2007.

[32] X. Zhang, G. Tao, and Z. Zhu, "Laboratory study of the influence of dip and ore width on gravity flow during longitudinal sublevel caving," International Journal of Rock Mechanics and Mining Sciences, vol. 103, pp. 179-185, 2018.

[33] C. Zhang and S. Tu, "Control technology of direct passing karstic collapse pillar in longwall top-coal caving mining," Natural Hazards, vol. 84, no. 1, pp. 1-18, 2016.

[34] F. Melo, F. Vivanco, C. Fuentes, and V. Apablaza, "On drawbody shapes: from Bergmark-Roos to kinematic models," International Journal of Rock Mechanics and Mining Sciences, vol. 44, no. 1, pp. 77-86, 2007.

[35] F. Y. Ren, L. Yang, J. L. Cao et al., "Prediction of the caved rock zones' scope induced by caving mining method," PLoS One, vol. 13, no. 8, Article ID e0202221, 2018.

[36] R. X. He, F. Y. Ren, B. H. Tan, and Y. Liu, "Distribution law of granular lateral pressure in caved ore-rock with limited width," Journal of Northeastern University (Natural Science), vol. 40, no. 3, pp. 108-112, 2019, in Chinese. 